\title{
SEXUAL DEVELOPMENT IN THE MONGOLIAN GERBIL, MERIONES UNGUICULATUS, WITH PARTICULAR REFERENCE TO THE OVARY
}

\author{
M. L. NORRIS AND C. E. ADAMS \\ A.R.C. Unit of Reproductive Physiology and Biochemistry, \\ University of Cambridge*
}

(Received 22nd August 1973)

In the Mongolian gerbil, vaginal opening occurs at 40 to 60 days of age (Nakai, Nimura, Tamura, Shimizu \& Nishimura, 1960; Schwentker, 1963; Marston \& Chang, 1965), whilst the age of sexual maturity has been given as 9 to 12 weeks (Schwentker, 1963; Marston \& Chang, 1965). Recently, Norris \& Adams (1972a) estimated that the mean age at first conception was 75 days under the most favourable conditions, namely 60-day-old females paired with sexually experienced males. Normal growth data from birth to 150 days of age have been presented by Norris \& Adams (1972b). The present study was undertaken in order to obtain information on ovarian development in relation to puberty and sexual maturity in this species. Recently, Stark (1973) has reported on ovarian development in gerbils aged 0 to 21 days.

Observations were made on a total of fifteen female Mongolian gerbils which came from our own colony, details of which have been given elsewhere (Norris \& Adams, 1972b). They were selected from litters containing five young. Beginning at 20 days of age, animals were killed with an overdose of chloroform at 10-day intervals up to 100 days, and thereafter at 140 and 170 days. After removal of the whole genital tract, the ovaries and uterine horns were separated, weighed and then fixed in Bouin's fluid before dehydration and embedding. The ovaries were sectioned at $8 \mu \mathrm{m}$ and all of the sections were mounted and stained with eosin and haematoxylin. Subsequently, antral follicles were counted and classified according to their stage of development, as described by Pedersen \& Peters (1968) for the mouse. All follicles and oocytes were measured through the centre of their largest cross-section, two measurements being made at right angles to each other, using an eyepiece $(\times 6)$ graticule (E17, Graticules Ltd, London) and objective $(\times 10)$ for follicles, and an ocular micrometer $(\times 12 \cdot 5$, Leitz, Wetzlar $)$ and objective $(\times 40)$ for oocytes. The numbers of atretic follicles and of corpora lutea, whenever present, were recorded.

The data relating to the animals' body weights, and ovarian and uterine weights are shown diagrammatically in Text-fig. 1. The body weights conform with the normal growth curve (Norris \& Adams, 1972b). A marked increase in ovarian weight occurred between 30 and 40 days of age, after which there was

* Postal address: 307 Huntingdon Road, Cambridge, CB3 0JQ. 


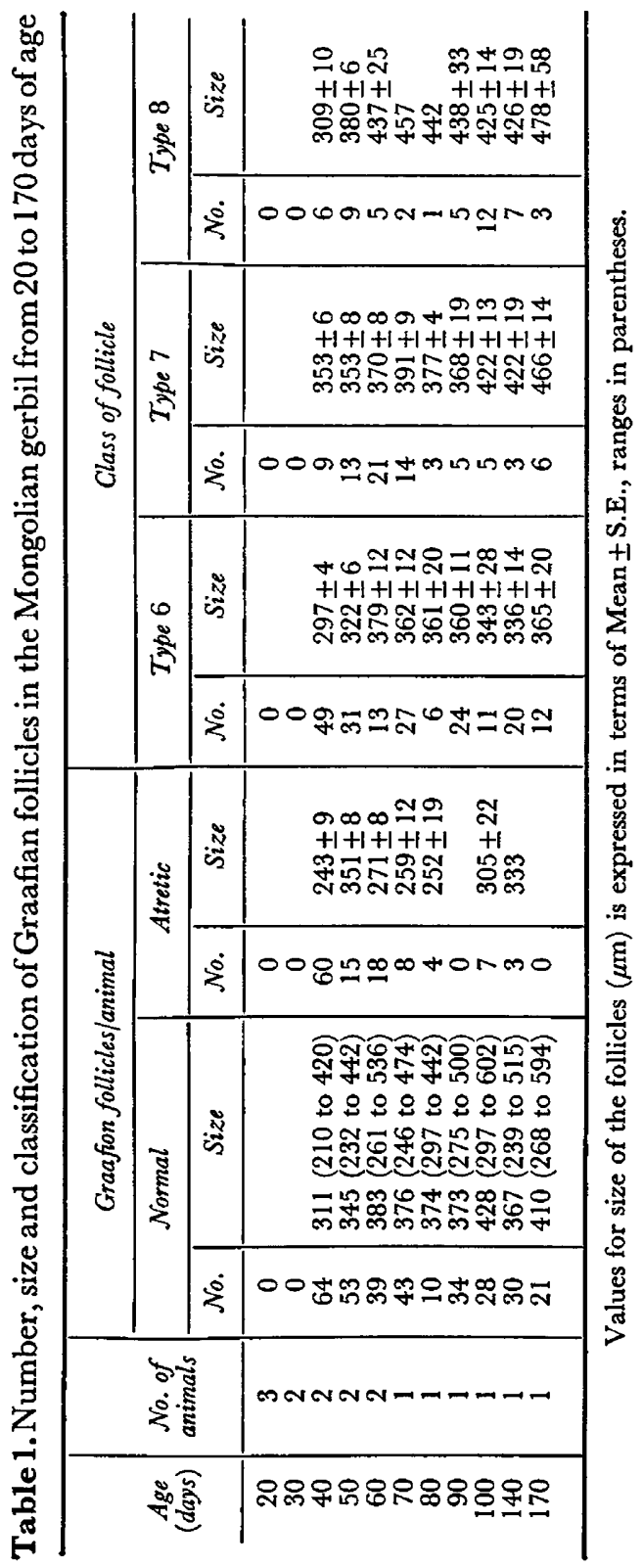


little further change until corpora lutea appeared at 90 days. The uterus showed a rapid gain in weight between 30 and 60 days of age.

Details of the numbers, mean size and developmental stage of Graafian follicles present in the ovaries of Mongolian gerbils aged 20 to 170 days are presented in Table 1. Antral follicles were first recorded at 40 days of age, when the mean number present/ovary was thirty-two. Over the next 30 days, their number declined so that after 70 days of age each ovary contained no more than ten to fifteen follicles. The proportions of Type 6,7 and 8 follicles remained

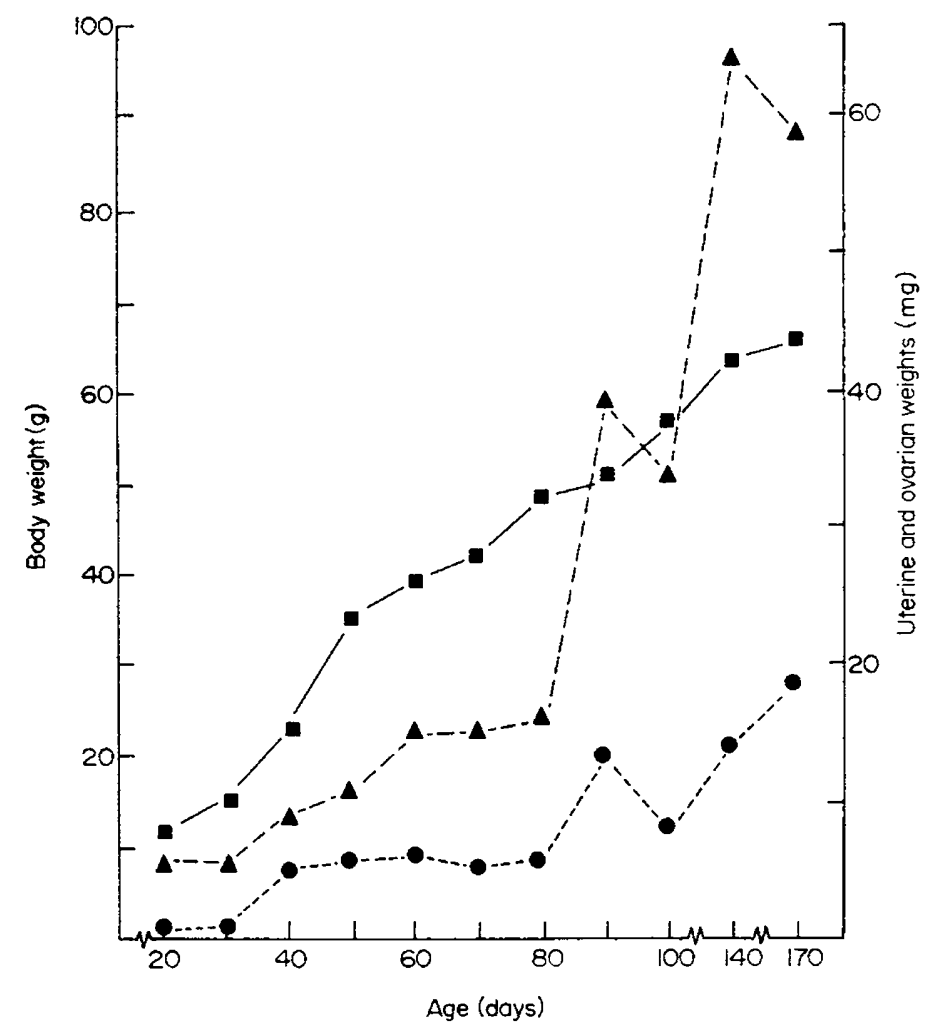

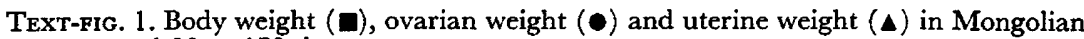
gerbils, aged 20 to 170 days.

relatively constant at $60 \%, 25 \%$ and $15 \%$, respectively. The first Graafian follicles to appear at 40 to 50 days were appreciably smaller than those recorded from 60 days onwards, and $17 \%$ of the follicles were classified as atretic, their incidence being highest $(31 \%)$ in animals aged 50 to 60 days and coinciding with the decline in follicle numbers. The position appears to be quite similar in the BALB/C mouse where a wave of follicular maturation occurs at 2 to 3 weeks of age and is closely followed by a wave of atresia (Gates, 1971). In the mouse, antral follicles not only appear earlier, from Day 20 onwards, according to Kent (1972) who used CFW mice, but their maximum number, as recorded by Gates (1971), is also about $2 \frac{1}{2}$ times greater than in the gerbil. 
The mean diameter of the vitellus in 339 oocytes was $66.0 \mu \mathrm{m}$, with an apparent diminution in size from $67.3 \mu \mathrm{m}$ (243 oocytes in Type 6 follicles), to $64.4 \mu \mathrm{m}$ (107 oocytes in Type 7 follicles) to $62.9 \mu \mathrm{m}$ (49 oocytes in Type 8 follicles), possibly due to differential shrinkage on fixation. In twenty-five eggs recovered shortly after ovulation, the mean diameter of the vitellus was 69.4 $\mu \mathrm{m}$ (Marston \& Chang, 1966). Whilst no significant difference in oocyte diameter attributable to age of female was discernible, there was considerable variation between females of the same age, and this was consistent for each follicle type. The zona pellucida varied in diameter from 8 to $10 \mu \mathrm{m}$; in newly ovulated eggs, it measured 8.4 $\mu \mathrm{m}$ (Marston \& Chang, 1966).

Recently, Fischer \& Fischer (1973) reported that superovulation can be induced in gerbils by treatment with PMSG and HCG at 5 to 6 weeks of age when averages of up to thirty-three ova recovered/animal were recorded. According to our findings, this probably represents the peak ovarian response.

\section{REFERENGES}

Fischer, T. V. \& FISCHER, D. L. (1973) Superovulation in the Mongolian gerbil. (Abstract). Anat. Rec. $175,319$.

Gates, A. H. (1971) Maximizing yield and developmental uniformity of eggs. In: Methods in Mammalian Embryology, p. 64. Ed. J. C. Daniel, Jr. Freeman, San Francisco.

KENT, J. (1972) Changes in the ovarian follicle population of mice aged 16 to 20 days. J. Reprod. Fert. 31, 323.

Marston, J. H. \& Ghang, M. C. (1965) The breeding, management and reproductive physiology of the Mongolian gerbil (Meriones unguiculatus). Lab. Anim. Care, 15, 34.

Marston, J. H. \& Ghang, M.C. (1966) The morphology and timing of fertilization and early cleavage in the Mongolian gerbil and Deer mouse. F. Embryol. exp. Morph. 15, 169.

Nakai, K., Nimura, H., Tamura, M., Shimizu, S. \& Nishimura, H. (1960) Reproduction and post natal development of the colony bred Meriones unguiculatus. Bull. exp. Anim., Tokyo, 9, 157.

Norris, M. L. \& Adams, G. E. (1972a) Aggressive behaviour and reproduction in the Mongolian gerbil, Meriones unguiculatus, relative to age and sexual experience at pairing. F. Reprod. Fert. 31, 447 .

Norris, M. L. \& ADAMs, C. E. (1972b) The growth of the Mongolian gerbil, Meriones unguiculatus, from birth to maturity. F. Zool., Lond. 166, 277.

Pedersen, T. \& Petrers, H. (1968) Proposal for a classification of oocytes and follicles in the mouse ovary. F. Reprod. Fert. 17, 555.

SCHWENTKER, V. (1963) The gerbil. A new laboratory animal. Illinois Vet. 6, 5.

Stark, R. A. (1973) Postnatal ovarian development in the Mongolian gerbil. (Abstract). Anat. Rec. 175,450 . 